\title{
MUSEU: ESPAÇO IMPULSIONADOR DE RECONFIGURAÇÓES IDENTITÁRIAS DOCENTES
}

\author{
Maria Isabel Leite*
}

\begin{abstract}
RESUMO: Este artigo busca perceber qual o papel que as exposiçôes museais assumem na constituição de identidades dos diferentes sujeitos-visitantes. Nessa linha, propõe um recorte em torno da relação de contemplação ativa de docentes junto aos objetos musealizados, em particular do Museu da Infância. Pode-se notar, em diálogo com Kramer, Arroyo e Nóvoa, que os artefatos (fotos, objetos escolares, entre outros) mostraram-se fonte desencadeadora de memória e reflexão crítica acerca das práticas pedagógicas correntes e passadas. Modos de ensinar e aprender são revisitados e a escola é tomada como espaço de problematização e crítica. A conclusão da análise dos dados destaca que o museu, para além do locus de preservação, é, também, espaço impulsionador de produção de sentidos; esfera promotora de reconfiguraçōes identitárias docentes, viabilizador de novas maneiras de se pensar os espaços de pedagógicos, deflagrando mudanças nas trajetórias pessoais/profissionais de professores.
\end{abstract}

Palavras-chave: Escola. Identidade. Professor. Produção de sentidos. Museu da Infância.

\section{MUSEUM: A PLACE THAT INSTIGATES TEACHERS' SELF-IDENTIFICATION}

ABSTRACT: This article aims to understand the role that exhibitions play in visitor's identity. Thus it suggests a special attention around the relationship between teachers and museum's objects, in particular, the ones from the Museum of Childhood. It's possible

Doutora em Educação, pesquisadora e consultora autônoma na área de Educação: infância, formação e espaços formais e não formais de educação. E-mail: leite.mariaisabel@gmail.com 
to observe, according to Kramer, Arroyo and Nóvoa, that museum's artifacts (as photographs, educative objects etc.) become memories' resources and improve critical reflection about current and old pedagogical practices. Different ways to teach and learn are reviewed, and also school is deemed as a place to be critically analyzed. Conclusions emphasize that museums can be considered not only places to preserve culture and nature, but also locus to increase meaning production; spaces that promote reflections about teacher's self-identification, showing new ways to thing pedagogical structures, improving changes in teacher's personal and professional choices/paths.

Key words: School. Identity. Teacher. Meaning production. Museum of Childhood.

\section{Para começo de conversa...}

$\mathbb{E}$

sse artigo vem problematizar o papel que as exposições museais podem assumir na constituição de identidades dos diferentes sujeitos-visitantes, em particular de professores. Para isso, propóe uma trama teórica que passa pelas concepções de museu, de professor e de professoralidades, e segue a tessitura bordando com fios narrativos advindos de depoimentos docentes espontâneos; ${ }^{1}$ e os acresce com dados sobre as exposições do Museu da Infância - locus investigativo privilegiado.

\section{O que dizer dos museus?}

O museu, do jeito que se pensa no senso comum, como espaço cheio de vitrines que servem para a apreciação e deleite do público, é uma criação do século XVIII, que viveu forte crescimento e expansão na Europa do século XIX. Foi um tempo em que espaços museais eram locais distanciados, que apresentavam a um público seleto objetos da, então, proclamada alta cultura, expostos de maneira intangível, reforçando a concepção de museu como local silencioso e sagrado; o museuguardião, com peças impenetráveis, que buscavam expressar um sentido uníssono.

Segundo Hein (1998), o início do século XIX, marcado pela industrialização, acompanhada da migração das populações do campo 
para as cidades, gerou a necessidade de os governos assumirem maior responsabilidade pelos serviços sociais e educacionais e, nesse sentido, os espaços museais europeus foram vistos como possíveis locais de educação para as massas. Contudo, de acordo com o autor, as escolas também faziam parte da expansão da educação para todos e, diferentemente dos museus, rapidamente se organizaram de forma que, ao final do século, já eclipsavam o papel educativo museal.

Foi no século XX, mais precisamente na França de 1950, que o conceito de museu foi sendo modificado, para tornar-se algo mais acessível ao público diverso, tendo sua dimensão pedagógica reexaminada.

Especialmente desde 1951, o Conselho Internacional de Museus (Icom) e a Organização das Nações Unidas para Educação, Ciência e Cultura (Unesco) vêm lutando pela consciência desse papel educativo nos museus - uma proposta que tenha como pressuposto o direito de todos os cidadãos à educação permanente, em todas as dimensôes culturais, sem esquivar-se da dimensão crítica do conhecimento. O museu é, então, uma das instâncias educativas da sociedade - entendendo educação como indissociável da cultura. (Leite, 2005, p. 28)

$\mathrm{Na}$ mesma direção do impulso de cumprir um papel educativo, se fez cada vez mais presente na relação público-museu a ideia de abertura, de acolhimento do diverso, de processo e, portanto, de inacabamento. Malraux (1965) aponta que uma das principais questôes que vinham se instaurando na ocasião, no âmbito da cultura, em particular das artes, era "a ausência - a recusa - do acabado" (p. 51). Assim como "a Arte entra em conflito com o 'acabado', com testemunho de nossos sentidos (...)" (p. 57), também os museus, como qualquer instituição social dinâmica e viva, se transmutam e se repensam e, ao longo do tempo, diluem suas paredes erguidas na solidez da certeza e tornam-se pouco a pouco flexíveis, porosos ao seu entorno. Nessa direção, os museus vão, paulatinamente, tirando as coleções do foco e invertendo o pendão do protagonismo para o contemplador.

Ainda na década de 1960, Malraux extrapola sua teoria, propondo o conceito de um Museu Imaginário. Da mesma maneira que o museu tradicional foi criado com um determinado propósito de preservação de manutenção do status quo, o Museu Imaginário de Malraux vem quebrar com essa barreira ao extremo, considerando o contemplador como sujeito capaz de produzir sentidos e fazer relaçôes; criar laços e 
Museu: espaço impulsionador de reconfigurações identitárias docentes

estabelecer comparações e contextualizações possíveis entre aquilo que já foi visto, evocando imagens retidas, criando assim seu próprio museu, que reúne tudo o que desejar.

Milene Chiovatto, professora universitária em São Paulo, informante da pesquisa que embasa esse texto, define os museus e problematiza seu papel social:

O Museu é um espaço de resguardo de memória e, portanto, o que nele se guarda faz parte da cultura coletiva. Mesmo que você seja excluído dos âmbitos oficiais de cultura, de alguma forma a cultura na qual vive está ali constituída... Assim, não há como visitar um museu sem, ao construir suas interpretações sobre os objetos, constituir-se como identidade!.

Portanto, antes subordinado ao objeto, receptor de uma mensagem hermética, o contemplador contemporâneo compõe o discurso museal; é coautor. Olhando por esse prisma, evocam-se as ideias de Malraux no que tange a capacidade que temos de consumir criticamente aquilo que é oferecido nos espaços museais e, consequentemente, nossas possibilidades de dar significação àquilo que é visto, ouvido, sentido, experienciado num museu.

Dessa forma, o contemplador é reconhecido em sua capacidade intrínseca de produzir cultura; de dialogar com o seu entorno, de problematizar os bens culturais e naturais aos quais acede. A forma como os museus se estruturam hoje deixa de solicitar do público aquela antiga atitude passiva, convidando-o a assumir uma postura de contemplador ativo - que, num ininterrupto movimento de aproximação e distanciamento, tensão e distensão, vai tecendo uma trama entre sua experiência presente, a passada e sua imaginação. Como depõe Andressa Silva, professora de educação infantil da rede pública de Florianópolis (SC):

Arrepiei-me quando visitei a exposição sobre samba no Paço Imperial, no Rio de Janeiro, em 2008. Nunca me interessei por samba, embora eu tenha crescido ouvindo os discos de samba que meu pai comprava. Nesse dia, não tinha muito tempo para ficar ali, (...) mas não conseguia sair dali e não sei explicar o que senti. Até hoje percebo o samba de outro modo e passei a gostar de ouvir.

Segundo salienta Kramer (1998, p. 210): “(...) no museu, o mais importante não é o que vemos, mas que possamos construir um modo de olhar em que razão e sensibilidade aliadas teçam uma maneira crítica 
e sensível de ver as coisas e de compreender suas histórias”. Dessa forma, os sujeitos passam a não mais somente ver o objeto, mas também a ver-se no objeto, como mostra Silemar Silva, professora universitária e professora de arte, do ensino fundamental na rede pública de Criciúma (SC), em seu depoimento:

No Museu Augusto Casagrande o envolvimento maior - para mim - foi com a mobília que ficou me lembrando a casa de uma tia querida (irmã de minha mãe), uma casa no sítio com portas altas, corredores estreitos e móveis de madeira maciça, pesada e cheia de histórias. Foi na minha primeira infância, íamos para casa dela e passávamos o final se semana - o que era muito frequente. Ali vi a BR-101 sendo construída, vivenciei a experiência de não ter energia e nem água encanada em casa, e dormia com peneiro. Falo isso porque não havia mais pensado nessa fase de minha vida (na década de 60), nessa história, e ao ver aqueles objetos antigos e aquele baú (que a mediadora disse que não era baú, e sim um porta-mantimento), minhas memórias foram se reconstruindo e formando outras. (...). Nossa, sou filha dessa cidade [Criciúma/SC], com pai, sogro e marido mineiros, como não viajar nas locomotivas estampadas nas histórias da cidade? Essa Casa do Ferroviário é uma espécie de "casa da memória”; são doces lembranças que vão te constituindo enquanto sujeito.

\section{Afinando a escuta: conhecendo um pouco do Museu da Infância ${ }^{2}$}

O Museu da Infância, campo investigativo privilegiado nesse artigo, foi criado em 2005 como Projeto de Extensão do Programa de PósGraduação em Educação da Universidade do Extremo Sul Catarinense (Unesc). Desde então, consubstancia-se como um espaço de preservação, produção e circulação da produção científica e artístico-cultural para, sobre e $d a$ infância, visando contribuir para ampliação de repertório artístico-cultural de crianças e adultos, na reformulação dos processos de formação de educadores, nos projetos de ação pedagógica das escolas e demais instâncias culturais, dando subsídios para pesquisadores da infância e para políticas públicas de educação e de acesso à cultura.

Seu vínculo com as escolas e professores, explicitado em sua missão, concretiza-se em inúmeras parcerias e buscas incessantes por diálogo por meio de oficinas, ciclos de filmes e debates, exposiçôes, entre outras atividades. Na leitura de Arroyo (2000), poder-se-ia ainda inferir que a vinculação entre o Museu da Infância, professores e escolas - triângulo 
Museu: espaço impulsionador de reconfigurações identitárias docentes

de interesse deste texto - se origina na forte cumplicidade existente entre a infância e a Pedagogia, o "que marcou profundamente o ofício e a imagem de mestre-educadores" (p. 39). Segundo o autor, "[n]o espelho da história da infância descobrimos traços de nosso rosto. Infância e Pedagogia, um caso não resolvido, insolúvel, que nem a teimosia do tecnicismo conseguiu romper" (idem).

$\mathrm{Na}$ tentativa de dar conta de seus muitos desafios e propostas, o Museu da Infância tem se assumido como um espaço sem fronteiras rígidas; mais permeável às trocas com seu entorno; receptivo, acolhedor; locus de descobertas e aguçamento de sentidos daqueles que por ele transitam, carregando suas marcas históricas, sociais e culturais, as quais lhes asseguram um olhar singular ao dar significação ao visto/ouvido/sentido no Museu.

Nessa direção, para a organização de suas exposiçōes, o Museu da Infância toma como referência estética o conceito de instalação, algo que não mais se vê de fora, mas em que se entra; com o que se estabelece relaçôes de pertença. Isso é feito porque se busca uma proposta que convide o espectador a tomar posição - um convite permanente a uma revisão/reconfiguração identitária. Essa questão é claramente abordada nos dois depoimentos que se seguem - de Celia Flores, professora de educação infantil e de ensino fundamental da rede privada do Rio de Janeiro, e de Chiovatto (op. cit.): "Creio realmente que todas as experiências nos marcam e mexem, de alguma forma, mesmo que apenas reforçando conceitos, com nossa identidade"; "Além da identidade da pessoa, a identidade como docente se reforça ao experimentar o potencial educativo do museu".

Assim, partindo da ideia de que um museu guarda objetos/imagens que foram especiais para as pessoas, ou para uma comunidade, sociedade ou época, isto é, seus tesouros, aquele que o contempla também aciona seus próprios tesouros, compostos por suas memórias, sonhos, histórias, imaginação e experiências anteriores.

$\mathrm{Na}$ busca de desencavar os tesouros de cada contemplador, o $\mathrm{Mu}$ seu da Infância organiza exposições temáticas que buscam favorecer reflexões. Exemplifico com três delas: na exposição Infância e Paz, o Museu assume o desafio de provocar a percepção da inteireza humana como possibilidade de busca da paz. Organizada em forma de mandala, para representar a não assimetria de forças, expôs uma mostra do seu acervo 
sobre, da e para a infância, que variava do artesanal ao industrial, com alguns objetos bem recentes e outros datando do início do século XX, sobretudo um conjunto de bonecas e bonecos de materiais variados, elaborados em diferentes tempos e espaços, representando a diversidade de infâncias. O objetivo era que, do circuito expositivo, se integrassem as múltiplas infâncias presentes em cada espectador - afinal, o que nos torna humanos é exatamente aquilo que nos diferencia; e que, da integração advinda do olhar crítico e reflexivo, se buscasse o respeito ao outro, o que contribuiria para a noção de paz. Silva (op. cit.) comentou sobre a exposição em seu depoimento para essa pesquisa:

O Museu da Infância, por mais que eu conhecesse sobre ele, quando vi aquele baú com tule e trabalho das crianças [na exposição Infância e Paz]... Foi mágico! A ludicidade estava presente, me senti criança, professora de criança e professora de professora (...). Tenho acompanhado o trabalho do Museu da Infância, e isso tem contribuído muito na minha formação enquanto professora.

Em Culturas Infantis na Ibero-América, o objetivo era pensar criticamente produções da, para e sobre as crianças em países desta região. Esta mostra disponibilizou poesias, pinturas, brinquedos, imagens de crianças em produção, mídias diversas, bem como informações acerca das diferentes realidades vividas por tantos meninos e meninas. Trazer à tona uma diversidade de olhares acerca da infância intencionou reiterar a ideia de que não há infância única e padronizada, mas uma multiplicidade de modos de ser criança nos diferentes tempos e espaços. Houve ainda um ciclo de filmes sobre a infância, feitos por diretores ibero-americanos. Esses aspectos comunicacionais mais amplos foram destacados pela mesma professora, Silva (op. cit.), em suas respostas ao questionário:

O repertório de filmes, livros, brinquedos, jogos e músicas que o Museu da Infância vem mostrando, questionando e divulgando é algo que contribui diretamente com nossa opinião sobre como e o que mostrar para as crianças em nossas salas de aula, no sentido de ampliar um repertório significativo para elas (...). A forma como o Museu tem valorizado a produção das crianças, evidenciado essa produção com respeito, é algo que vem nos ensinando a sermos cada vez mais sensíveis ao sujeito criança enquanto produtor de cultura (...). A relação com o Museu da Infância tem fomentado reflexôes sobre essa postura adultocêntrica que ainda carrego nas entrelinhas de minha ação pedagógica (...). 
Museu: espaço impulsionador de reconfigurações identitárias docentes

Essa mesma exposição Culturas Infantis na Ibero-América foi também abordada por Ana Maria Cambruzzi, professora universitária aposentada de Minas Gerais:

[Se eu levasse uma turma de professoras em formação], alguns objetos poderiam ser selecionados pelas visitantes a fim de apreendê-los de forma mais significativa [no trabalho junto às turmas de alunos]. Por exemplo: - mapa dos países ibero-americanos e a reprodução de obras de pintores dos respectivos lugares: que escala foi utilizada para construir esse mapa? O que significa olhar e caminhar sobre esse mapa? Conhecemos os pintores que foram selecionados para representar os países ibero-americanos? De que "falam" as obras aqui reproduzidas? Esses pintores retratam que cultura? Que terras? Que pessoas? Que atividades? O que significa ibero-americano? Em que aspectos das pinturas podemos encontrar o pensamento mestiço, ou seja, há entrelaçamento da cultura conquistadora e a cultura nativa? Em que obras encontramos esses aspectos culturais?

Por fim, tomo o exemplo da exposição Infância e Culturas Escolares. Sempre na perspectiva de ressignificar o conceito de museu e de exposição, nessa mostra os objetos da cultura escolar foram tanto expostos e musealizados, quanto utilizados como suporte para expressão plástica de crianças; como ainda serviram cenograficamente de base para a ambientação de objetos, textos e imagens. Nesse contexto, procurou-se colocar os contempladores na posição de coautores: não só foram convidados a se posicionar diante de polêmicas pedagógicas e/ou enfrentar jogos com desafios lógico-matemáticos, mas também lhes foi destinado espaço para registro de suas memórias escolares e, ainda, recolhido material para a exposição junto à comunidade. Mais uma vez, Silva (op. cit.) sublinha, em seu depoimento, essa perspectiva de constituição identitária e o sentimento de pertença: "Essa exposição foi algo marcante, primeiro porque pude participar emprestando algumas peças de minha vida escolar, as quais contracenaram com peças da infância de minha filha, e com tantas outras infâncias que ali se fizeram presentes".

O Museu da Infância entende que pensar criticamente as infâncias e culturas escolares é assumir as especificidades dos valores, ações, objetos, ritos e ritmos produzidos nas instituições de ensino formal. Nesse sentido, destaco o comentário da professora Andressa Silva sobre essa exposição: "A exposição Infância e Culturas Escolares me fez sentir curiosidade e surpresa; repensar sobre a história da educação, principalmente se estou certa em pensar que há poucos materiais e registros publicados". 


\section{De professores e professoralidades}

Para pensar sobre professoralidades busco, em Nóvoa (1991, 1992), entender a profissionalidade específica dos docentes: "Entendemos por profissionalidade a afirmação do que é específico na acção docente, isto é, o conjunto de comportamentos, conhecimentos, destrezas, atitudes e valores que constituem a especificidade de ser professor" (1991, p. 64).

Sobre isso, Cambruzzi (op. cit.) analisa em seu depoimento essa investigação:

Revejo-me [a cada visita museal] com possibilidade de refletir sobre algumas práticas. Para tanto, tomo como parâmetro a memória de minha atuação enquanto professora da disciplina Metodologia de Ensino do curso de Pedagogia (...). O sentido de se visitar um museu com aprendizes de docência é possibilitar a própria ampliação cultural, incluindo nela questôes que dizem respeito às representaçôes simbólicas e estéticas; a lida concreta com a seleçâao de objetos e materiais que apresentam significados para serem musealizados e com a disposição dos objetos no espaço físico.

O jeito de ser professor - ou seja, o conceito de profissionalidade de que trata Nóvoa (1991), é dinâmico e provisório, uma vez que não é descolado do contexto sociopolítico e econômico pelo qual a profissão está sempre atravessada. Ressalta o autor que, no caso dos docentes, embora não negue a existência de conhecimentos específicos inerentes à professoralidade, pensar as especificidades de suas ações não é tarefa fácil por estas serem múltiplas e menos delimitadas do que aquelas referentes a outras profissōes liberais clássicas.

Sobretudo, argumenta que se pode entender o professor como "gestor de dilemas", ou seja, sua atuação "consiste em tomar decisōes num processo que se vai moldando e adquire identidade enquanto ocorre, no decurso do qual se apresentam opçôes alternativas, face às quais é necessário tomar uma decisão" (Nóvoa, op. cit., p. 87). A resposta ao questionário dada pelo professor universitário Julio Romero Rodriguez, de Madrid, Espanha, vem nessa direção:

Na última exposição do Museu da Infância, destaco a valorização que eu via de todos os objetos e elementos apresentados ali; a importância que a equipe dava a quase qualquer coisa, ao mundo cotidiano - o que fazia com 
Museu: espaço impulsionador de reconfigurações identitárias docentes

que essas coisas se voltassem, importantes e reconhecidas, como portadoras de cultura. Assim, eu aprendi, ou (re)aprendi, como a cultura é algo que construímos constantemente, e provisoriamente, e que só depende de onde queiramos olhar e com que intenção. Também a infância como criadora de cultura; nós todos, em geral, como criadores de cultura, e a importância de resgatar tudo isso. Então, minha prática docente se transforma, dando mais importância e visibilidade às histórias dos alunos, suas biografias, suas criações, e tentando sempre que eles também tenham esse olhar como futuros professores e aprendam a ser eles mesmos.

Não se pode entender que a identidade profissional dos professores é algo dado ou estático, ao se considerar as questôes e reflexôes de Nóvoa acerca de professoralidade. $\mathrm{O}$ autor destaca o fato de que:

(...) a escolha de uma profissão e a trajetória de trabalho de um indivíduo resultam de múltiplos factores: implicam redes de relações sociais e culturais tecidas a diversos níveis e atravessadas por lógicas próprias, feitas de acasos e circunstâncias, de aspiraçôes e de constrangimentos, de coincidências e decisões. (Idem, ibid., p. 178)

Sublinha ainda que, "[c]ontendo ou estimulando, facilitando ou inibindo, as estruturas profissionais interagem com os destinos pessoais, dando-lhes contornos gerais que só se compreendem no quadro de processos coletivos" (ibid.).

Sobre essa dinâmica intrínseca à constituição identitária, destaco o depoimento da professora Andressa Silva (op. cit.):

Nossa identidade está sempre em formação. Na medida em que nos relacionamos com o outro, ocorre uma relação de mão dupla com trocas que não são passivas, pois, do mesmo modo que refletem, também refratam. Como penso que, na condição de professora de educação infantil, tenho o compromisso de ampliar o repertório cultural das crianças, a visita a museus mexe com minha identidade, me faz repensar, amplia meu conhecimento, minha sensibilidade e me oferece mais repertório.

Arroyo (2000, p. 46) defende que a prática docente pode ser alargada com o aprendizado de "diversos processos e diversas manifestaçóes do desenvolvimento humano fora da escola" - e, de acordo com essa investigação, o museu assume destaque nesse cenário.

Nóvoa (1991) amplia esse aspecto quando ressalta que a professoralidade não se constitui como fruto exclusivo de ações individuais, mas 
como atitude coletiva, de classe; como ações que não permitem desconectar o eu-pessoal-singular do eu-profissional-plural; da mesma forma que não desvincula a identidade do sujeito, de sua identidade profissional como professor; bem como não descola o professor da escola, com suas práticas, ritos e ritmos.

Nessa direção, Kramer (1995, p. 87) contribui com a reflexão sobre a identidade docente quando alerta que, às vezes, professores, "ao invés de serem vistos como cidadãos que são, a partir de seus diferentes contextos sociais e culturais, de suas histórias de vida e de sua pertinência de classe, são expropriados até mesmo de sua identidade". A autora exemplifica com o fato de que muitas professoras aceitam ser chamadas de tias, representando, segunda ela, um tratamento pseudoafetivo e homogeneizante, "substituindo até mesmo a identificação do seu nome que, por ser próprio, é posse e marca social de cada um...” (idem, ibid.).

Estreitando o foco: o que os professores-visitantes dizem dos museus?

Como espaços onde se aprende com a cultura e não somente sobre a cultura, os museus possibilitam que os sujeitos vejam o mundo a sua volta e vejam-se no mundo, em seus diferentes papéis e identidades multifacetadas.

Refletindo sobre a estreita relação entre apropriação cultural e ação docente, Nóvoa (op. cit., p. 67) destaca que "[e]ducar e ensinar é, sobretudo, permitir um contacto com a cultura, na acepção mais geral do termo; trata-se de um processo em que a própria experiência cultural do professor é determinante". O autor baseia seus argumentos na afirmação de que "[o] ensino é uma prática social, não só porque se concretiza na interacção entre professores e alunos, mas também porque estes actores refletem a cultura e os contextos sociais a que pertencem" (p. 66).

Esta perspectiva social da educação é trazida no depoimento da professora Silemar Silva (op. cit.):

Como não sentir o desejo de falar sobre [a visita museal], de falar para os meus alunos, de pensar a possibilidade de socializar a experiência? (...). Visitar museus mexe com minha identidade como um todo e, nesse todo, encontro a professora que vai se formando a cada ampliação de repertório conquistada nessas visitas. 
Museu: espaço impulsionador de reconfigurações identitárias docentes

Dessa forma, partindo-se da relação de contemplação ativa de professores-visitantes junto aos objetos musealizados, é possível perceber que esses artefatos não se mostram neutros, mas fontes desencadeadoras de memória e reflexão crítica acerca de suas práticas docentes atuais ou passadas - tanto aquelas experienciadas como alunos que foram, quanto aquelas vividas como professores em formação continuada -, favorecendo novos olhares sobre suas as ações pedagógicas. Como destaca a professora Ana Maria Cambruzzi (op. cit.):

Enquanto professora provinda da disciplina Didática e Prática de Ensino, estar em algumas das atividades do Museu da Infância possibilitame lidar com aspectos de vida criativa: utilização de espaços, o significado de objetos selecionados para exposições, composição de cores na exposição, observação da materialidade dos objetos, a alegria de estar em movimento com coisas e pessoas.

Kramer (1995) já salientava, em sua pesquisa junto às professoras, o quanto os objetos e, em particular, as fotografias eram elementos impulsionadores da memória. Como escrita pela luz, a fotografia ilumina cenas em nossa memória afetiva e, em diálogo com nosso campo racional e também com nossa imaginação, possibilita ressignificar experiências, reconfigurar identidades.

Arroyo (2000, p. 17), narrando a experiência que teve em uma exposição de "velhas fotos da vida escolar, de seus mestres e alunos", conta da perplexidade das professoras diante daquele encontro: "aquelas fotos eram mais do que memória da escola, eram sua Memória (...). No silêncio de seus olhares, uma viagem de volta a um presente incômodo redescoberto na Memória". Seriam essas "professoras de hoje" tão diferentes daquelas "professoras de ontem"? Ao verem $o$ outro, entendem a si, pois se veem no outro.

Essa questão identitária pode ser ampliada e percebida para além da relação com as imagens: "[o] acesso aos bens culturais é meio de sensibilização pessoal que possibilita, ao sujeito, apropriar-se de múltiplas linguagens, tornando-o mais aberto para a relação com o outro, favorecendo a percepção de identidade e de alteridade" (Leite, 2005, p. 23).

Nesse sentido, na visita a uma exposição museal, modos de ensinar e aprender podem ser revisitados e a escola, tomada como espaço 
de problematização e crítica - como aparece na resposta da professora Celia Flores (op. cit.) ao questionário:

Posso dizer que a todo o tempo busco caminhos para minha prática, inclusive ao visitar museus. Todas as vezes que visito um museu - seja ele de Arte, ou de qualquer outro tipo - sempre me pego pensando em algum momento sobre como isso pode chegar aos alunos com os quais interajo, que tipos diversos de experiências tais informações (ou imagens) podem propiciar (...).

Para Kramer (1995, p. 61), o professor é um "mediador entre os alunos e o conhecimento, que interage com as crianças, estabelece regras e se liga a elas afetivamente das mais variadas formas". É ressaltada pela autora a impossibilidade de um educador - seja de crianças, ou de adultos - deixar de fora seus outros papéis sociais quando está numa sala de aula, da mesma maneira que aponto que esse papel de educador não é deixado de lado quando se está num museu. Em outras palavras,

[o] trabalho dos professores precisa ser entendido a partir de uma perspectiva que dê conta de pensar o homem em sua totalidade e em sua singularidade (...). Eles são sujeitos históricos. São produtores de linguagem. Linguagem que os constitui sujeitos humanos e sociais sempre imersos em uma coletividade. (Kramer \& Jobim, 1996, p. 15)

\section{Para a professora Milene Chiovatto,}

[é] natural que, quando um professor visite um museu, seja tocado pela função educativa do museu, vislumbrando ali potenciais para sua prática pedagógica. Entretanto, acho que um bom professor faz isso com tudo o que toca... uma espécie de "Midas" educativo, ou seja, percebe potenciais educativos em tudo que lhe cai nas mãos ou lhe entra pelos olhos e ouvidos (...). Também devo dizer que é impossível adquirir uma informação na visita ao museu, sem que isso altere as conexões com as demais informações que você - como docente - já possui... Nada como estar frente à frente com o objeto real!

$\mathrm{Na}$ mesma direção do depoimento de Chiovatto, Gómez (in: Nóvoa, 1992, p. 110) defende que "[o] profissional competente actua refletindo na acção, criando uma nova realidade, experimentando, corrigindo e inventando através do diálogo que estabelece com a realidade". E o museu, sem dúvida, é um espaço social que faz emergir diversas facetas da realidade. 


\section{Museu como espaço impulsionador de reconfigurações identitárias docentes}

Museus são, sobretudo, espaços de significação, lugares de experiência formativa que transita na interface da cognição com o sensível. Nesse sentido, defendo que o museu pode ser entendido como locus, também, de marcação de uma identidade docente. Se Nóvoa (1992, p. 25) afirma que urge "(re)encontrar espaços de interacção entre as dimensōes pessoais e profissionais, permitindo aos professores apropriar-se dos seus próprios processos de formação", esta investigação vem apontar que os museus estão, paulatinamente, servindo a esse propósito.

Moussouri (2007) também defende que toda experiência museal é, de certa forma, uma experiência de constituição identitária. Para a autora, na medida em que o sujeito contemplador reconhece/estranha aquilo que é visto, pode ver-se nos objetos/artefatos expostos e, assim, (re)visitar seus valores, suas próprias histórias. Moussouri (op. cit.), baseada na teoria de Vigotski, afirma que as pessoas aprendem na experiência coletiva, mais do que individualmente - e a experiência museal é, sobretudo, uma experiência cultural coletiva, na qual há várias materialidades/subjetividades, espacialidades e temporalidades em interação: sejam as que envolvem o sujeito-contemplador, sejam aquelas referentes ao sujeito-autor, e ainda as concernentes aos objetos em si. Em outras palavras, é "no diálogo com o outro e com a cultura que cada um é constituído, desconstruído, reconstruído, cotidianamente" (Leite, 2005, p. 23).

Essa permanente teia de questionamentos e bordados envolvendo passado, futuro e presente, em múltiplos ângulos, foi destacada no depoimento do professor Julio Romero Rodrigues (op. cit.):

$\mathrm{Na}$ última exposição do Museu da Infância que eu vi, a informação era substituída por perguntas. Perguntas ao visitante, perguntas a mim. Esse giro eu achei muito importante. É um sinal de participação, implicação, de museu em construção, uma possibilidade de participar criando experiência, conhecimento, cultura, um convite para fazer parte. Desde então, observo que minha prática docente se encheu de perguntas para os alunos. Já não estou só interessado em informar, explicar, mostrar, mas em perguntar, semear dúvidas, questionar, abrir debates, estimular a imaginação e a participação. Ou estou interessado muito mais que antes e de maneira mais consciente. E observo que as perguntas, e não as informações, geram assim muito mais implicação, participação e busca de cada 
um entre suas próprias ideias, experiências, pontos de vista. Gosto muito dessa ideia: de que o conhecimento não esteja no professor, mas nos alunos, e que o olhar para as coisas cotidianas, suas próprias ideias e crenças, sua biografia e a atitude de perguntar sejam protagonistas.

Assim como apresentado no relato do professor Rodrigues, a ação docente, a partir de visitas museais, pode mudar de protagonismo, bem como o museu também pode ser entendido para além do conceito original que o toma como locus de preservação, produção e difusão de artefatos culturais. Isso ocorre na medida em que o museu seja conceituado/ percebido como: a) esfera impulsionadora de produção de sentidos por aqueles que o frequentam; b) espaço promotor de reconfigurações identitárias (no caso deste artigo, docentes); e c) provocador de mudanças nas trajetórias pessoais/profissionais dos sujeitos contempladores. Assim, quem sabe, o museu também se tornará viabilizador de novas maneiras de se pensar os espaços pedagógicos.

\section{Notas}

1. Todos os que estão aqui nominados autorizaram o uso de seus depoimentos e nomes completos.

2. Os dados sobre o Museu da Infância foram retirados de <www.museudainfancia.unesc.net>. Não foram usadas aspas, pois sou autora/coautora de todo o material aqui utilizado.

\section{Referências}

ARROYO, M. Ofício de mestre: imagens e autoimagens. Rio de Janeiro: Vozes, 2000.

HEIN, G.E. Learning in the museum. New York: Routledge, 1998.

KRAMER, S. Alfabetização, leitura e escrita: formação de professores em curso. Rio de Janeiro: Papéis e Cópias da Escola de Professores, 1995.

KRAMER, S. Produção cultural e educação: algumas reflexões críticas sobre educar com museu. In: KRAMER, S.; LEITE, M.I. (Org.). Infância e produção cultural. Campinas: Papirus, 1998. p. 199-215.

KRAMER, S.; JOBIM E SOUZA, S. (Org.). Histórias de professores: leitura, escrita e pesquisa em educação. Rio de Janeiro: Ática, 1996. 
Museu: espaço impulsionador de reconfigurações identitárias docentes

LEITE, M.I. Museu de Arte: espaços de educação e cultura. In: LEITE. M.I.; OSTETTO, L.E. (Org.). Museu, educação e cultura: encontros de crianças e professores com a arte. Campinas: Papirus, 2005. p. $19-54$.

MALRAUX, A. O museu imaginário. Lisboa: Edições 70, 1965.

MOUSSOURI, T. Visitor research in the 2000's: are the challenges really new? Palestra proferida no Annual Group Meeting (AGM) do Visitor Study Group (VSG), na British Library, 13 fev. 2007. (mimeo.).

NÓVOA, A. (Org.). Profissão professor. Porto: Porto Editora, 1991.

NÓVOA, A. Os professores e sua formação. Lisboa: Dom Quixote, 1992.

Recebido em $1^{\circ}$ de setembro de 2010.

Aprovado em 17 de março de 2011. 